\title{
A PRODUÇÃO DO ESPAÇO URBANO E A QUESTÃO DOS RESÍDUOS SÓLIDOS
}

\author{
Urban space production and the \\ question of solid residues
}

\author{
Janaina Natali ANTONIO ${ }^{1}$ \\ Marquiana de Freitas Vilas Boas GOMES ${ }^{2}$
}

\section{RESUMO}

O presente artigo discute sobre o espaço urbano como produto das relações entre a sociedade e a natureza, produzido com ênfase em interesses econômicos. Dessa forma as dimensões sociais e ambientais são deixadas em segundo plano, tendo como conseqüências uma série de problemas. Entre eles destacamos, os relacionados à alta produção dos resíduos sólidos urbanos impulsionada pelos padrões capitalistas de consumo e agravados pela sua destinação inadequada .

Palavras-chave: sociedade; natureza; espaço urbano; resíduos sólidos.

\begin{abstract}
This article discusses the urban space as product of relations between society and nature, with emphasis on economic interests. Thus the social and environmental dimensions are leave the background, the consequences being a series of problems, between detach, those related to the high production of urban solid residues driven by capitalist patterns of consumption and aggravated by inadequate in their destination.
\end{abstract}

Keywords: society; nature; urban space; solid residues.

1 Mestranda em Gestão do Território do Departamento de Geociências - Universidade Estadual de Ponta Grossa - UEPG.

2 Docente do Departamento de Geografia - Universidade Estadual do Centro-Oeste - Unicentro. Doutoranda em Geografia na Faculdade de Ciências e Tecnologia da Universidade Estadual Paulista - Unesp, Campus de Presidente Prudente. 


\section{INTRODUÇÃO}

Em busca de compreender as atuais questões ambientais e seus problemas, principalmente os que se referem aos resíduos sólidos, entendemos que seja necessário compreender qual a dinâmica das relações entre a sociedade e a natureza e os fatores que contribuíram para sua existência e/ou aumento.

Partimos dos apontamentos de Rodrigues (1998) de que para se alcançar esse entendimento é preciso não separar a natureza da sociedade, rompendo com a concepção dessa como um agente externo e com função única de servir o homem, e desse, como ser superior.

É preciso pensar a natureza na sua globalidade e dinâmica, considerando a diversidade social e as formas pelas quais a sociedade a transforma e produz o espaço social.

Esse espaço é produzido socialmente, e surge como uma categoria representável para a análise científica, podendo ser encarado como um elo palpável de articulação da sociedade com a natureza e com as demais forças que agem no seu processo de produção.

Lacoste (1988) propõe que pensar o espaço envolve apreendê-lo em sua totalidade, ou seja, temos que ter uma visão ampla e conjunta de suas interações, outro apontamento sobre o espaço que merece atenção é a de Milton Santos (1991, p. 27),

O espaço deve ser considerado como um conjunto indissociável de que participam, de um lado, certo arranjo de objetos geográficos, objetos naturais e objetos espaciais, e, de outro, a vida que os preenche e os anima, ou seja, a sociedade em movimento. O conteúdo (da sociedade) não é independente da forma (os objetos geográficos), e cada forma encerra uma fração do conteúdo. O espaço, por conseguinte, é isto: um conjunto de formas contendo cada qual frações da sociedade em movimento. As formas, pois, têm um papel na realização social.

Nesse contexto, natureza e sociedade são indissociáveis, assim como as categorias espaço e tempo. Daí que a compreensão ambiental requer o entendimento dessas categorias/conceitos. Ocorre que há uma relação temporo-espacial no ambiente, uma vez que a capacidade de exploração da natureza, por equipamentos industriais e tecnológicos, é muito maior que a regeneração dos recursos naturais, o que intensifica a gravidade dos problemas.

E quando esses são percebidos pela sociedade dado a escassez dos recursos naturais, inicia-se uma maior preocupação em relação a questão tanto no campo quanto na cidade.

$\mathrm{Na}$ cidade eles se manifestam no ar, na água, no solo, enfim na paisagem urbana de forma intensa. Pois a cidade tornou-se o lócus de concentração de pessoas, produção e serviços, e por consequência a sobrecarga dos problemas ambientais, dentre os quais, neste artigo, destacamos aqueles relacionados aos resíduos sólidos.

Os resíduos sólidos surgem como um problema, principalmente nos centros urbanos, que além do grande aumento e concentração da população, nem sempre contam com um sistema de gerenciamento adequado, sendo que, muitas vezes, a sua destinação final é feita em áreas sem controle e/ou tratamento.

Considerando que a questão dos resíduos, está diretamente relacionada à dinâmica da sociedade capitalista e urbana, a forma e o ritmo de ocupação nas cidades, a produção e o consumo, e a concepção que a sociedade tem sobre o "lixo", entendemos que é importante compreender o processo que envolve essa questão em sua totalidade, para conhecer elementos mais adequados que possam auxiliar na questão dos resíduos sólidos.

Neste artigo, portanto, iremos abordar a produção do espaço sobre o ponto de vista da apropriação da natureza pela sociedade capitalista, e as suas relações com a questão dos resíduos sólidos no espaço urbano.

\section{A PRODUÇÃO DO ESPAÇO E AS RELAÇÕES ENTRE A SOCIEDADE E A NATUREZA}

Na geografia o conceito de espaço adquire importância fundamental sendo reconhecido como um de seus conceitos norteadores. Como aponta Suertegaray (2001) o espaço se constituíra, na categoria central para a Geografia que, por vezes, confunde-se com o seu próprio objeto.

Essa categoria é concebida de forma e grau de importância distinta dentro das correntes da geografia e entre os autores, que são influenciados por momentos históricos, necessidades e interesses. Conforme Harvey (1973 apud CORRÊA, 1995) as diferentes práticas humanas estabelecem os diferentes conceitos de espaço, conceitos que sob determinadas circunstâncias passam a ser por nós empregados.

Com eclosão da corrente crítica da geografia, que no Brasil se deu a partir da década de 80 do século XX, influenciada pelo livro de Lacoste $^{3}$ (1988), busca pro-

3 LACOSTE, Y. A geografia - isso serve, em primeiro lugar, para fazer a guerra. Campinas: Papirus, 1988. 
blematizar a geografia como um saber estratégico, importante para o conhecimento e ação do/no espaço.

Essa corrente, fundamentada no materialismo histórico e na dialética, pauta-se nas discussões atreladas às lutas de classes, ao sistema econômico e as atividades materiais e produtivas que dão alicerce para a organização espacial. E conforme Suertegaray (2001 s.p.):

Neste momento, parte da Geografia passa a preocupar-se com o espaço geográfico, entendendo-o como resultado das formas como os homens organizam sua vida e suas formas de produção. Nesta perspectiva, a Geografia concebe a relação natureza-sociedade sob a ótica da apropriação, concebendo a natureza como recurso à produção.

Conforme Lefebvre (1976) o espaço desempenha um papel e/ou uma função decisiva na estruturação da totalidade, de uma lógica, de um sistema, reconhecido também como o lócus de reprodução das relações sociais de produção. Santos (1996) também trata sobre a importância do conhecimento sobre a totalidade, que é entendida como a realidade em sua integridade, para o conhecimento sobre as partes do Todo, e assim sua explicação conjunta.

Milton Santos (1977) afirma não ser possível conceber uma determinada formação sócio-econômica sem se recorrer ao espaço. Segundo ele, modo de produção, formação socioeconômica e espaço são categorias interdependentes, de modo que as formas espaciais constituem uma linguagem dos modos de produção.

A produção do espaço está atrelada à forma de apropriação da natureza e a sua relação com a sociedade e o capital, a partir disso a base material é construída e as relações sociais e culturais reproduzidas. Atribui-se a Lefebvre a criação da expressão "produção do espaço", que considera que o espaço "estaria essencialmente vinculado com a reprodução das relações (sociais) de produção" (LEFEBVRE, 1976, p. 34).

O espaço passa a ser visto como um resultado direto da produção material e atuação do homem na natureza, e segundo Smith (1988, p. 109) "a menos que o espaço seja conceituado como realidade completamente separada da natureza, a produção do espaço é um resultado lógico da produção da natureza." Daí a necessidade de entender as relações entre sociedade e natureza, pois são as relações responsáveis pela produção do espaço.

Até certo tempo, a natureza era vista como independe da ação humana, vista como aquilo que não pode ser produzido, a antítese da atividade produtiva humana, em que o homem era encarado como um ser superior e a natureza um recurso a ser dominado para sua utilização. Essa dominação da natureza é uma realidade aceita por todos, quer ela seja vista com espanto ou com temor (SMITH, 1988).

Primeiramente as alterações feitas na natureza eram unicamente para a subsistência dos seres humanos, porém passa-se de uma produção de consumo próprio para uma produção de excedentes para a troca, que será a base para o novo sistema econômico, que permanece até os dias atuais.

As alterações na natureza justificam-se pela necessidade do progresso pela acumulação de capital e expansão do desenvolvimento econômico que a torna cada vez mais um produto social, e que conforme Harvey (2005, p. 198):

As "forças da natureza" se sujeitam ao controle humano: os maquinários, a utilização da química para a indústria e agricultura, a navegação a vapor, as ferrovias, os telégrafos, a roçadura de continentes inteiros para o cultivo, a canalização dos rios, a expulsão de populações inteiras do campo [...]

Alterações que cada vez realizados em maior escala e recebendo interferências, com o passar do tempo, causam graves conseqüências, principalmente no aparecimento dos problemas ambientais que a sociedade vem enfrentando como assoreamento dos rios, poluição do ar e das águas, ilhas de calor, deslizamentos de encostas, ausência de vegetação, acúmulo de resíduos sólidos, entre outros.

O conjunto desses problemas nos remete a questionamentos sobre a questão ambiental, e conforme Rodrigues (1998, p. 13):

(re)coloca em destaque contradições da produção social do espaço e das formas de apropriação da natureza. Formas de apropriação tanto reais - as formas concretas pelas quais a natureza é transformada -, como simbólicas -, o pensamento sobre estas apropriações e transformações.

O problema está, na ação destrutiva e despreocupada com a natureza em detrimento das relações de produção, incluindo a do espaço urbano, em que muitas vezes desconsidera-se que a base física para a construção das estruturas materiais também fazem parte da natureza. Para compreender a questão ambiental é preciso que ela seja encarada como produto da intervenção da sociedade sobre a natureza.

Tão grandes foram as mudanças realizadas na natureza pela ação humana que "a sociedade não mais aceita o espaço como um receptáculo, mas sim 
o produz; nós não vivemos, atuamos ou trabalhamos 'no' espaço, mas sim produzimos o espaço, vivendo, atuando e trabalhando" (SMITH, 1988, p. 132).

Os problemas ambientais, porém, não devem ser encarados somente como resultado das relações homem/natureza, mas também às relações entre os homens, sem ocultar as contradições de classes existentes.

O processo de produção do espaço por meio das alterações realizadas na natureza está intimamente ligada ao capitalismo, contribuindo para esta observação Lefebvre (1976), em suas considerações, aponta que o capitalismo sobreviveu no século XX por um único meio: "pela ocupação do espaço, pela produção do espaço".

Segundo Smith (1988, p. 94):

A produção capitalista (e a apropriação da natureza) é acompanhada não pela satisfação das necessidades em geral, mas pela satisfação de uma necessidade em particular: lucro. Na busca do lucro, o capital corre o mundo inteiro. Ele coloca uma etiqueta de preço em qualquer coisa que ele vê, e a partir desta etiqueta de preço é que se determina o destino das coisas.

Levando em conta o processo produtivo e suas necessidades de expansão, cada ponto do espaço torna-se então importante, efetivamente ou potencialmente. Tal importância decorre de suas próprias virtualidades, que podem ser naturais ou sociais, preexistentes ou adquiridas segundo intervenções seletivas, de forma que se a produção se mundializa, as possibilidades de cada lugar se afirmam e se diferenciam em nível mundial. (SANTOS, 1991)

A partir da busca incessante pelo lucro, a natureza é apenas matéria-prima para a satisfação de necessidades, aumentando a produção/destrutiva, à criação de novas necessidades que não satisfazem necessidades humanas enriquecedoras, mas apenas correspondem a modos de vida da sociedade do descartável. Predominase a produção de mercadorias - que duram cada vez menos - e utiliza-se de forma intensiva o espaço para produzir mais, intensificando a problemática ambiental. (RODRIGUES, 1998)

Observando como são realizadas as relações entre a natureza e a sociedade e a força exercida pelo capital nas formas de produção do espaço, é possível notar que os problemas ambientais são gerados por uma apropriação inadequada e exagerada da natureza em busca de lucros imediatos, sem preocupação com o futuro.

Os problemas são, em maior escala, observá- veis no ambiente urbano em que a concentração da população, indústrias, construções, fluxos comerciais e de informação, que levam a alterações ainda maiores na natureza, questão que pretendemos abordar, enfocando dentro da lógica descrita, sobre a produção dos resíduos sólidos e suas conseqüências no espaço urbano produzido pelas relações materiais, sociais e capitalistas de produção.

\section{OS RESÍDUOS SÓLIDOS NO ESPAÇO URBANO}

Dentro da perspectiva exposta seguimos com a concepção de Corrêa (1995) em que o espaço urbano capitalista é um produto social, resultado de ações acumuladas pelo tempo, e produzidas por agentes que produzem e consomem o espaço. São agentes sociais concretos. A ação desses agentes é complexa, derivando da dinâmica de acumulação de capital, das necessidades mutáveis de reprodução das relações de produção, e dos conflitos sociais que dela emergem.

O capitalismo, com seu objetivo de acumulação de capital, envolve todas as esferas da sociedade, e, por conseqüência, todas as relações espaciais são de ordem social, de forma que podemos considerar o espaço urbano como um reflexo da sociedade. (CORRÊA, 1995)

A concentração populacional nos centros urbanos traz consigo uma série de efeitos sociais e ambientais, em que, de um lado, está às mudanças de padrões e quantidades de consumo, e de outro uma precarização em relação aos aglomerados urbanos, sobretudo, nas áreas de assentamento das classes mais baixas.

O desenvolvimento capitalista, pautado na produção, circulação e distribuição de mercadorias, promoveu a criação de uma cultura na qual a cidade representa "desenvolvimento" e modernidade. Conceito esse questionável, pois o desenvolvimento que se defende é apenas o econômico, ignorando suas outras dimensões social, cultural e ambiental.

Esse discurso faz com que a cidade seja o foco de atração populacional, de destino de muitos trabaIhadores do campo, pois representa a concentração do comércio e de serviços e, com isso, passa a ser vista como "centro" de oportunidades.

No entanto, o que acabam encontrando na cidade, via de regra, é uma realidade distinta da que imaginavam. Muitos têm dificuldade para encontrar trabalho, e acabam em subempregos nos quais não ganham o suficiente para a sua subsistência, sendo levados a morar em sítios físicos como as planícies de inundação e as vertentes íngremes, na qual não podem 
lançar mão de soluções de engenharia adequadas à edificação, vivendo de forma insalubre, tendo em vista que a cidade não oferece infra-estrutura suficiente a toda à população. (BITOUN, 2005)

Conforme o Manual Global de Ecologia (2002, p. 50):

Poucos governos podem prover moradia adequada, água potável, saneamento, escolas, transporte e outros serviços a tais populações em crescimento. Áreas mal planejadas se expandem, construções se tornam decrépitas, e a poluição degrada o ar e contamina os locais de fornecimento de água.

Desta forma, aqueles que possuem menores condições financeiras ocupam as áreas periféricas e terrenos que pela racionalidade técnica, deveriam ser mantidos em estado natural. $\mathrm{O}$ uso de palavras como "morros" e "alagados" para designar os espaços urbanos do habitat das famílias pobres revela um consenso, mantido pela sociedade local, para segregar a problemática da relação entre urbanização e a natureza do modelo de desenvolvimento urbano. (BITOUN, 2005)

É notável, portanto, a relação entre esse aumento demográfico e a degradação do meio ambiente. Contudo, é importante ressaltar que não podemos atrelar os problemas ambientais única e exclusivamente ao aumento da população, sob pena de não acabarmos por legitimar uma visão "malthusiana" de mundo, mas sim problematizar essa concentração populacional nas cidades capitalistas, no contexto das desigualdades sociais, na estratificação social e, sobretudo, na distribuição desigual de renda (MORATO, 2005).

Principalmente, porque ao materializar na paisagem urbana essas diferenças sociais, percebe-se também a desigualdade ambiental, uma vez que não há uma socialização dos problemas ambientais entre a população, pelo contrário, é a população mais carente que acaba por ocupar os locais mais degradados e a sofrer mais diretamente com os problemas ambientais (MORATO, 2005).

Os avanços tecnológicos na indústria levaram a criação de novos produtos, facilitaram a disseminação uma nova cultura de consumo, que altera as atitudes da sociedade em relação à produção de resíduos, produzidos em quantidades cada vez maiores. A lógica é dos descartáveis, que tornam a vida mais prática, mas em contrapartida têm conseqüências graves ao ambiente. A esse respeito Cortez menciona que (2002, p. 1):

Em paralelo à urbanização, têm-se as mudanças naturais que vão ocorrendo na sociedade, traduzidas em tecnologias mais sofisticadas, nas mudanças de hábitos, nos padrões de consumo. A sociedade moderna tem como valores importantes o consumo, o estoque, a quantidade, a substituição por objetos mais novos e, portanto, um descarte de materiais que ainda poderiam ser utilizados ou reciclados.

Assim, o ambiente urbano apresenta-se como o palco da maior produção de resíduos sólidos, pela alta densidade demográfica, avanços na tecnologia e difusão da mídia, além de representar o centro das distribuições comerciais que age de forma dinâmica e impulsiona o desejo de consumir.

Um exemplo disto são os altos índices de resíduos coletados nas regiões metropolitanas do Brasil apresentados pelo Instituto Brasileiro de Geografia e Estatística na Pesquisa Nacional de Saneamento Básico - PSNB de 2000 (Quadro 1).

\begin{tabular}{|c|c|}
\hline Regiões Metropolitanas do país & $\begin{array}{c}\text { Quantidade diária de lixo coletado } \\
\text { (t/dia) }\end{array}$ \\
\hline Belém & $2.697,0$ \\
\hline Fortaleza & $7.211,2$ \\
\hline Recife & $3.221,0$ \\
\hline Salvador & $2.940,5$ \\
\hline Belo Horizonte & $6.889,7$ \\
\hline Rio de Janeiro & $13.429,4$ \\
\hline São Paulo & $83.066,9$ \\
\hline Campinas & $3.508,2$ \\
\hline Curitiba & $2.131,8$ \\
\hline Porto Alegre & $3.566,2$ \\
\hline Goiânia & $3.709,7$ \\
\hline
\end{tabular}

QUADRO 1 - QUANTIDADE DIÁRIA DE LIXO COLETADO EM T/DIA, NAS REGIÕES METROPOLITANAS DO PAÍS FONTE: IBGE, Pesquisa Nacional de Saneamento Básico, 2000. 
Segundo a PSNB (2000) há uma tendência de aumento da geração informada do lixo domiciliar per capita em proporção direta com o número de habitantes. Nas cidades com até 200.000 habitantes, pode-se estimar a quantidade coletada, variando entre 450 e 700 gramas por habitante/dia; acima de 200 mil habitantes, essa quantidade aumenta para a faixa entre 800 e 1 200 gramas por habitante / dia (Gráfico 1).

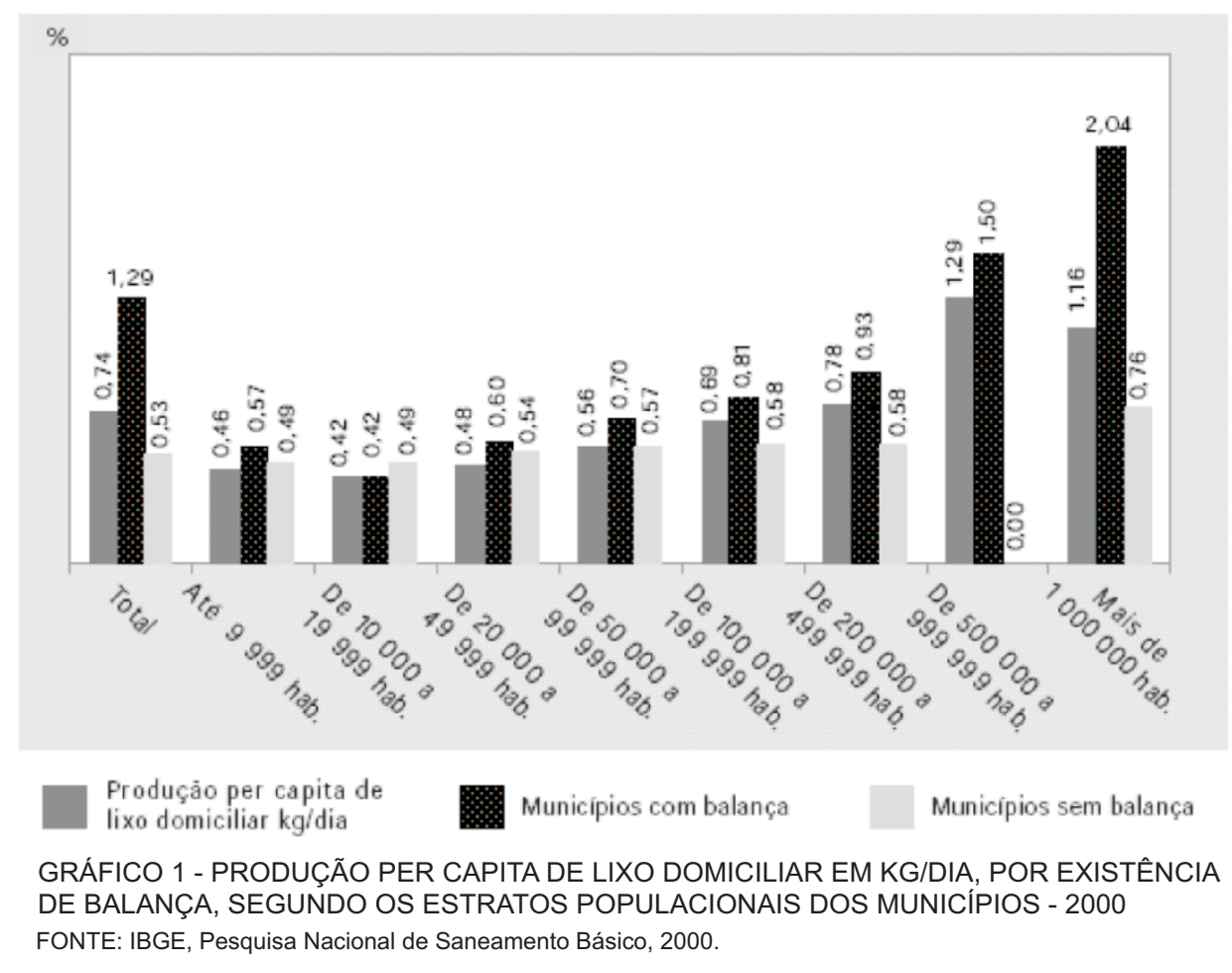

Outro exemplo é a pesquisa de Antonio, et. al. (2007) realizada em Guarapuava-PR sobre a concentração da produção dos resíduos sólidos urbanos, que obteve como resultados a alta concentração nas áreas centrais e nos bairros em que a população possui maior poder aquisitivo, e baixa concentração nos bairros periféricos e que ainda possuem algumas características rurais.

Dentro desse contexto os estudos relacionados com a problemática da produção e destinação dos resíduos sólidos vêm ganhando destaque, pois está diretamente ligada a sociedade de consumo. Além disso, os sistemas públicos como prefeituras, os quais são responsáveis pelo gerenciamento desses resíduos na cidade tem buscado tratar o assunto com mais seriedade, sobretudo a partir da fiscalização pelos órgãos ambientais.

Os problemas, causados pelos resíduos sólidos, não são unicamente causados pelo aumento da produção de resíduos, mas pelo tratamento inadequado que recebem.

Na grande parte das cidades os resíduos sólidos têm como destino final os depósitos, nos quais o lixo é simplesmente descarregado sem qualquer tratamento, e em alguns casos, também são dispostos resíduos industriais e de serviços de saúde, de forma descontrolada, e sem medidas prévias de proteção ao meio ambiente ou à saúde pública. Além, da poluição visual, mau odor e desvalorização imobiliária da região, entre outros, que não são levadas em consideração pelos planos imediatistas de destinação final dos resíduos urbanos.

De acordo com dados da PNSB (2000) 63,6\% dos municípios utilizam lixões e $32,2 \%$, aterros adequados (13,8\% sanitários, $18,4 \%$ aterros controlados), sendo que 5\% não informaram para onde vão seus resíduos. Em 1989, a PNSB mostrava que o percentual de municípios que vazavam seus resíduos de forma adequada era de apenas $10,7 \%$.

Percebe-se assim, melhora da situação da disposição final do lixo no Brasil nos últimos anos, porém, muitos planos ainda não, visam à solução do problema, mas sim apenas afastá-lo das residências, transferindo-o para outro lugar, geralmente para locais periféricos longe dos olhos da população, criando a falsa impressão de que o problema dos resíduos foi resolvido. A esse respeito, vale lembrar a consideração 
apresentada pela Cetesb (1998, p. 44):

Outro conceito que carece de revisão é quanto à responsabilidade pelo lixo. No que diz respeito à sociedade, ela não se encerra no momento em que o lixo é colocado à porta para a coleta. É imprescindível que a população tenha consciência da quantidade que gera e descarta e para onde esse resíduo é enviado e como é tratado.

Voltamos aqui na discussão sobre a relação entre a sociedade e a natureza, agora de forma mais direta com os cidadãos e gestores públicos, que devem assumir sua responsabilidade sobre a produção dos resíduos sólidos e a destinação que esses devem receber para que não levem às conseqüências danosas ao ambiente.

A questão dos resíduos sólidos deve ser entendida na base de sua produção, e não apenas preocupar-se em reparar os danos após tomar dimensões catastróficas, portanto, é importante localizar onde o problema se inicia e nesse ponto atuar, sem é claro descontextualizalo das escalas mais amplas.

\section{ALGUMAS CONSIDERAÇÕES}

É possível claramente perceber a relação existente entre o modo de apropriação da natureza pela sociedade e suas conseqüências sociais, culturais e ambientais, que recebem maior força por meio da ação do capital na produção do espaço.

Há dependência entre acumulação do capital e a produção do espaço, pois sem as possibilidades da expansão geográfica, de uma reorganização espacial e do desenvolvimento geográfico desigual, o capitalismo, teria encontrado problemas para funcionar como sistema econômico e político ou teria assumido uma nova forma de organização.

Por meio da leitura do espaço, é possível compreender os interesses e contradições envolvidas em sua produção, bem como outros processos envolvidos dentro da lógica do capital. Em meio a essa contradição deparamo-nos com a discussão ambiental que recebe destaque pelos diversos e graves problemas causados pela exploração excessiva da natureza, em que se busca após a destruição, encontrar maneiras de neutralizar as conseqüências da exploração.

Os resíduos sólidos aparecem como um problema graças ao aumento demasiado de sua produção e disposição inadequada, principalmente no espaço urbano, em que o princípio para melhoria dessa situação é a minimização da geração e um aproveitamento mais racional dos recursos, uma vez que o ideal seria rever o sistema de produção e os valores predominantes na sociedade capitalista.

Para que a problemática ambiental possa receber os cuidados adequados e os resíduos sólidos possam ser encarados de outra forma, é preciso atuar sobre as causas do problema e não apenas buscar soluções superficiais que atingem apenas as conseqüências. É preciso atuar diretamente em suas causas, rever os conceitos de consumo e as formas de apropriação da natureza, e, sobretudo a atuação capitalista sobre o espaço.

\section{REFERÊNCIAS}

ANTONIO, J. N.; ASSUNÇÃO, E. F.; GOMES, M. F. V. B. A produção e o gerenciamento dos resíduos sólidos domiciliares na cidade de Guarapuava-PR. Terra Plural. v.1, n. 2, 2007.

BITON, J. Os embates entre as questões ambientais e sociais no urbano. In: CARLOS, A. F. A.; LEMOS, A. I. G. (Orgs.). Dilemas urbanos: Novas abordagens sobre a cidade. 2. ed. São Paulo: Contexto, 2005.

BRANCO, S. M. O meio ambiente em debate. São Paulo: Moderna, 1988.

CETESB. A cidade e o lixo. São Paulo: Secretaria de Estado de Meio Ambiente, 1998.

CORRÊA, R. L. O espaço urbano. São Paulo: Àtica, 1995.

CORRÊA, R. L. Espaço um conceito chave na geografia. In: CASTRO, I. E. de. et al. (Orgs.). Geografia: conceitos e temas. 2. ed. Rio de Janeiro: Bertrand Brasil, 2000.

CORTEZ, A. T. C. A questão de resíduos sólidos domiciliares: coleta seletiva e reciclagem -A experiência de Rio Claro (SP). Tese (Doutorado), Universidade Estadual Paulista - UNESP, Rio Claro - SP, 2002.

HARVEY, D. A produção capitalista do espaço. São Paulo: Annablume, 2005.

IBGE. Pesquisa Nacional de Saneamento Básico - PNSB/2000. Rio de Janeiro: IBGE/DPE, 2002.

LACOSTE, Y. A geografia - isso serve, em primeiro lugar, para fazer a guerra. Campinas: Papirus, 1988.

LEFEBVRE, H. Espacio y Política. Barcelona: Península, 1976.

CORSON, W. H. Manual Global de Ecologia: o que você pode fazer a respeito da crise do meio ambiente. 4. ed. São Paulo: 
ANTONIO, J. N.; GOMES, M. F. V. B. A produção do espaço urbano e a questão dos resíduos sólidos

Augustus, 2002, $413 \mathrm{p}$.

MORATO, R. G. et al. Geoprocessamento para a análise da desigualdade ambiental na subprefeitura do Butantã. In: SIMPÓSIO BRASILEIRO DE GEOGRAFIA FÍSICA APLICADA, 9., 2005, São Paulo. Anais... São Paulo: AGB. Geografia. Tecnociência - Sociedade e Natureza, 2005, p. 2331-2338.

MOREIRA, R. O que é a geografia. São Paulo: Brasiliense, 1983.

PHILIPPI JR, A., et al. Curso de gestão ambiental. São Paulo: Manole, 2004.

RODRIGUES, A. M. Produção e consumo do e no espaço: problemática ambiental urbana. São Paulo: Hucitec, 1998.
SANTOS, M. Metamorfoses do espaço habitado. São Paulo: Hucitec, 1991.

SANTOS, M. Sociedade e espaco: a formacão social como teoria e como método. Boletim Paulista de Geografia. São Paulo: AGB, 1977.

SANTOS, M. A natureza do espaço: técnica e tempo, razão e emoção. São Paulo: Lucita, 1996.

SMITH, N. Desenvolvimento desigual. Tradução: Eduardo de Almeida Navarro, Rio de Janeiro: Bertrand Brasil, 1988.

SUERTEGARAY, D. A. Espaço Geográfico uno e múltiplo. Revista Electrónica de Geografía y Ciencias Sociales, n. 93, jul. 2001. Disponível em: <http://www.ub.es/geocrit/sn-93.htm> . Acesso em: 23/10/2007. 